\title{
Experiential Assessment of Urban Open Spaces in Doha
}

Article in Open House International · December 2013

CITATIONS

4

3 authors, including:

Ashraf M. Salama

University of Strathclyde

99 PUBLICATIONS 252 CITATIONS

SEE PROFILE
READS

18

Fatma Khalfani

Qatar University

4 PUBLICATIONS 6 CITATIONS

SEE PROFILE 


\title{
14. EXPERIENTIAL ASSESSMENT OF URBAN OPEN SPACES IN DOHA .
}

\section{Ashraf M. Salama, Fatma Khalfani, and Ahood Al-Maimani}

\begin{abstract}
The current fast track urban development process is an important characteristic of the city of Doha. No exploration or examination of its urban spaces, however, has been done before. This paper offers an experiential assessment of three key urban open spaces by examining their spatial and physical characteristics while implementing direct systematic observation and behavioural mapping procedure. Assessment results reveal important outcomes that include absence of physical aspects amenable for effective use while offering a pleasant experience for visitors. The findings contribute to an in-depth understanding of the qualities of the three spaces and the resulting use, activities, and behaviour representative of the inhabitants' spatial experience in those spaces. While the overall experience of users appear to be satisfactory, the results convey that there is an absence of landscape features and a dearth of green spaces and appropriate outdoor furniture, absence of adequate shaded areas and shading devices and a lack of children's facilities or specially designated areas for children. Addressing the lack of features that enhance people's activities and use of these spaces would contribute to making the spaces more conducive for use by different types of users and at different days and times.
\end{abstract}

Keywords: Experiential Assessment, Doha, Urban Open Spaces, Behavioural Mapping.

\section{INTRODUCTION}

Doha is undergoing massive urban growth and a considerable number of new urban areas are being developed or transformed. Earlier research on the city indicate the city is witnessing dramatic urban transformations (Salama and Gharib, 2012; Wiedmann, Salama, and Thierstein, 2012). United Nations records point out that it is anticipated that half of the world's population will be living in cities by year 2025 . The city of Doha would surpass that extrapolation since more than $80 \%$ of Qatar's population already resides in the capital. The overall urban environment is thus becoming more and more important in the daily lives of over 1.7 million inhabitants who live there. The qualities of urban spaces heavily impact on a wide range of elements and aspects of daily life such as living conditions, entertainment, and the attractiveness and appeal of urban open spaces (Salama and Wiedmann, 2013).

The regional and global importance of Doha has increased significantly over the past two decades and maintaining and sustaining the current growth of its urban population is seen as critical to the future development of the country. Hence, enhancing the quality and function of urban open spaces and the urban environment as whole is one of the most important considerations that would determine such a future. However, no examination of urban spaces has been done before nor exploration of whether emerging or transformed urban areas are supporting the needs of inhabitants.

The availability of attractive, accessible open spaces is an important feature of a liveable urban environment, for the inhabitants of cities and urban areas. Such importance is sometimes ignored or oversimplified when making decisions about land-use or when discussing the qualities of the built form. Urban open spaces in Doha are scattered around the city from its northern peripheries to its centre, and in the southwestern peripheries. Varying in form, function, and scale, some spaces are often located within enclave developments, or within larger urban interventions, while others represent portions of spaces with dense urban districts or open waterfronts. This paper examines three key urban spaces that are believed to cover a significant range of activities, services, and cater to people of different socio-economic and cultural backgrounds. In essence, the objective is to examine different physical and behavioural aspects through experiential analysis while applying a behavioural mapping procedure. The results uncover several characteristics about use and activ- 
ities of these spaces offer insights into their spatial qualities while revealing a number of positive aspects and deficiencies, which mandate the need for careful considerations of the design of future urban spaces in this rapidly growing city.

\section{NEEDS FOR AND CHARACTERISTICS OF URBAN OPEN SPACES}

It is argued that the importance of urban open spaces lies in the fact that they can satisfy certain basic human needs as well as offer particular interactive opportunities to a city's inhabitants (Woolley, 2003). These needs, respond to many features of human functioning, as for example the need for physical comfort, relaxation, enjoyment and social stimulation; therefore opportunities to concretise and fulfil such needs in open spaces should be given paramount consideration by urban planners and architects. The examination of the qualities and features of open spaces in order to determine of whether or not they fulfil such needs may provide valuable insight as to why some open spaces are filled with people while others are eluded or underused.

In physical terms, open spaces can be defined by their legal ownership and boundaries. The perception of who owns the space or has control over it is an important factor in determining its availability to public access. For example, while some open spaces, such as those within gated communities, are exclusive to a specific community, a group of individuals, or certain persons, others like public parks are more readily accessible to everyone. Undeniably, the types of open space and their accessibility can promote feelings of inclusion or exclusion, as experienced by people of different cultural backgrounds and socio-economic statuses. By classifying open spaces into public, semi-public and private spaces, there can be a better understanding of how such spaces are used and by whom (Newman, 1972). Public spaces can be identified as those spaces available to all city inhabitants such as parks, squares, open markets, and plazas. Semi-public spaces include spaces that have limited opening times to the public or are only accessible to a particular group. These include school playgrounds or spaces in or surrounding certain institutional buildings such as hospitals or university campuses; semi-private spaces also include those spaces that are exclusive to a particular group of individuals and which the ordinary public cannot access such as communal gardens or green spaces in gated communities, or courtyards leadings to houses or residential units. In contrast, private spaces are the simplest type in this classification as they include individual gardens and spaces that are clearly demarcated and only accessible to the owners and residents of the property.

Open spaces from the users' viewpoint are described as places that allow for a wide spectrum of necessary and/or optional social activities (Gehl, 1987). Necessary activities include going to and from workplaces, schools, hospitals and shopping areas or markets, while optional activities are exemplified by recreational places where people can enjoy walking, jogging, meditating, sitting, or just enjoying quality leisure time with family and friends. Such activities are dependent on the characteristics and qualities of the open space and the opportunities available for active or passive engagement with the space. In some urban contexts, however, optional social activities may become necessary social activities. In this respect, five types of needs have been identified to account for inhabitants' requirements in pubic open spaces; these include opportunities for comfort, relaxation, passive engagement, active engagement, and discovery (Carr, Francis, Rivlin, L. G., and Stone, 2012).

Comfort in open spaces represents the basic needs for food, drink, and shelter. It can be reasonably stated that without satisfying the need for comfort, it would be hard to imagine that other needs could be satisfied (Linday, 1978). Yet, in attempting to enjoy and profit from their time in open spaces, people sometimes tolerate major discomforts such as an army of annoying insects or lack of shading devices. Relaxation represents a more developed state of physical and mental ease (Jackson, 1981). Typically, the description of a space as relaxing refers to the users' experience more than to its physical characteristics. However, it should be noted that these are interdependent since physical characteristics significantly impact the degree of relaxation in a space.

Passive engagement is the third need for open spaces; this too may lead to a sense of relaxation. However, passive engagement represents an indirect experience as it involves only the need for interaction with the setting, without active involvement, as for example, watching a spectacular sunset, observing a flock of birds or simply enjoying a beautiful view in a natural setting. Active engagement is a more direct experience since it involves contact and interaction with others, whether with strangers or people known to them. Satisfying a need for discovery is the fifth reason people visit public open spaces; this use represents their desire for stimulation while at the same time seeking pleasurable experiences (Whyte, 1980).

Recent literature on the urban design discusses the need for urban open spaces and elabo- 
rates on their benefits (Chaftoe, 2008), which may offer health benefits when users exploit them for physical activity or just being outside in fresh open air. The beneficial opportunities for improving health and fitness and inculcating a sense of general well-being is becoming a vital consideration in the function and sustainability of open spaces, and is especially significant in light of increasing levels of heart disease and obesity resulting from inactive city lifestyles. Open spaces are also places that offer opportunities for informal and social encounters and learning, places where people can meet other people with different customs, norms, perceptions, and behaviours (Elsheshtawy, 2011).

Additionally, open spaces are places that can help promote the tolerance, acceptance and understanding which result from close interaction with others as opposed to the negative stereotyping that often occurs in mono-cultural settings (Salama and Gharib, 2012). In this sense, an acquired tolerance would help contribute to building up a sense of cohesion and even solidarity with the environment and its people, as for example when interaction occurs through spontaneous encounters or at organised festivals, events and gatherings (Elsheshtawy, 2011). These aspects and opportunities can also result in financial benefits, both directly and indirectly (Chaftoe, 2008). Direct benefits could result from the sale of refreshments, food, or souvenirs or market products, while indirect benefits can come from through the promotion of key

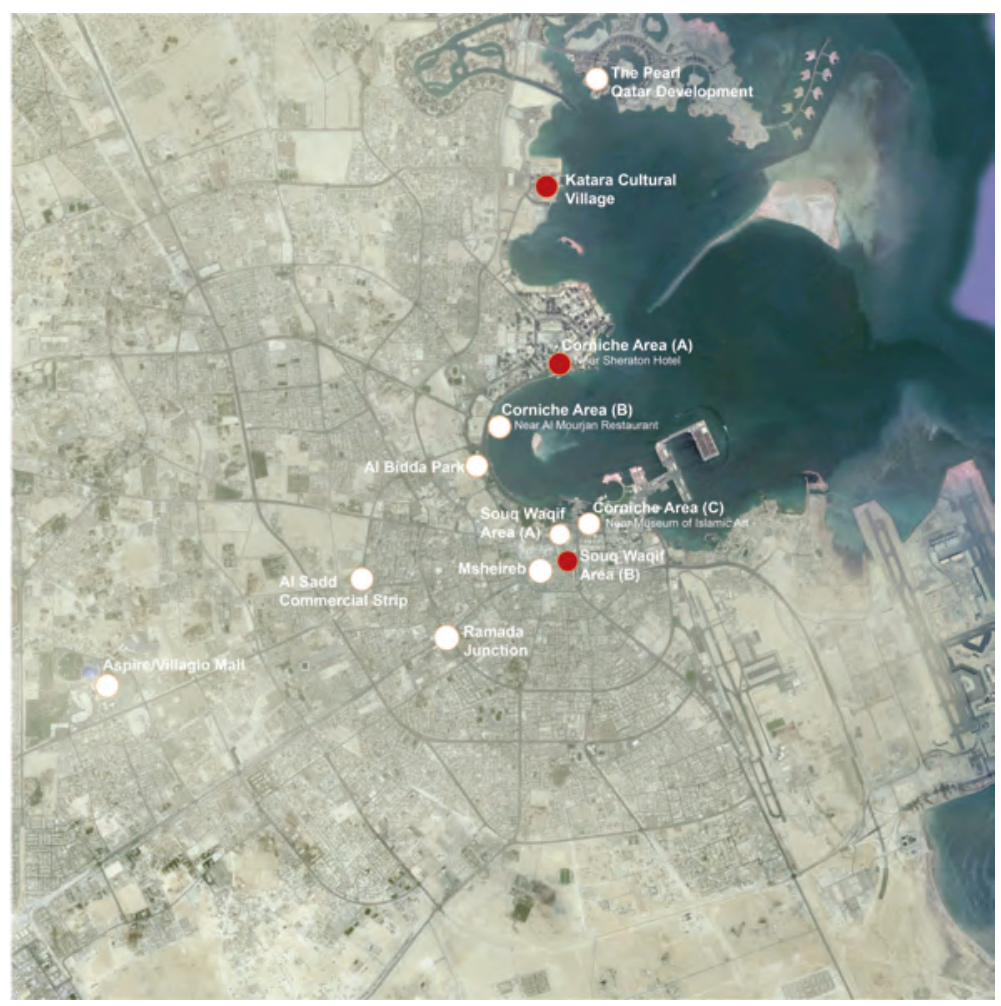

Figure 1. Location of the three urban spaces identified for conducting the assessment. (Source: Authors). spaces and their amenities and facilities that would attract visitors and tourists to the city who would then spend money and contribute to the economy of the locality.

\section{METHODOLOGY FOR EXPERIENTIAL ASSESSMENT}

In order to examine quality of urban open spaces an assessment mechanism was developed following a number of steps. Through earlier assessment of other aspects of urban open spaces in Doha (Salama and Gharib, 2012), the first was to identify spaces that need to be subjected to assessment. The second was to develop analytical portrayal of the spaces identified which would result in establishing descriptive profiles for each space. The spaces identified were the Katara Cultural Village, Corniche Area A, and Souq Waqif Area B (Figure 1). It should be noted that key areas within each space identified were selected to conduct the assessment.

The identification of the three spaces is based on the range of activities, services, and types of users that typify each space. Most important, the degree of 'publicness' was an important factor in identifying the spaces, where each enjoys certain aspects relevant to the qualities of being inclusive or exclusive, social, and symbolic (Dovey, 2002; Akkar, 2005; Varna and Tiesdell, 2010). The descriptive profile of each space involves a brief outline of the spatial typology, context accessibility, type of users, and nature of activities.

Direct observation and behavioural mapping is a systematic method for describing what visitors and users of a space actually do there. Observation and mapping are tools for understanding the dynamics of people and their interaction with the urban environment; it is an alternative approach to data collection that views people as 'objects' by recording their periodic behaviour. Valuable information can be obtained when behaviour is systematically recorded (Sanoff, 1991). Unplanned observation may result in inadequate findings that may reveal only what seems to be already obvious. Systematic observation of behaviour involves four aspects; these are: people, activities, setting or space, and timing.

In this procedure a combined unobtrusive mapping technique, which integrates 'place-centred' mapping and 
"individual-centred" mapping, is used. Place-centred mapping aims at observing actions in a particular setting or portion of a public space; these are recorded on floor plans, maps, or diagrams. Individual-centred mapping records the tasks, activities, and movements of people throughout the investigated space (Salama, 2012). It represents a systematic learning about a particular group of individuals whose activities are distributed throughout a specific period of time.

In planning the study, a series of visits to the three spaces was conducted to explore key settings within them; these were selected because of their importance in terms of intensity of visitors and variety of activities. Original maps were obtained and re-drawn and timings were identified: each of the spaces was observed twice during the week and twice at weekends. Times of observation varied on weekdays and at weekends. Observation took place on weekday mornings from 10.00 to 11.00 p.m. and during weekend mornings from 10.30 to $11.30 \mathrm{a} . \mathrm{m}$. For weekday and weekend evenings, observation times were from 6.30 to 7.30 p.m. and from 7.00 to 8.00 p.m., respectively. Users were classified into five groups: children, male visitors, female visitors, female domestic workers or cleaners, and male labourers. Maps were generated for each observation and mapping period and combined maps were then developed to illustrate the overall profile of behaviour and activities in each space.

\section{EXPERIENTIAL DESCRIPTION AND SPACE PROFILES}

Katara Cultural Village is named after the ancient name 'Catara' used by second century Roman mapmakers to designate the peninsula of Qatar. Katara, as it is popularly known, is a ninety-nine hectare development along the waterfront located slightly north of Doha, between the West Bay Financial District and The Pearl Qatar development. Its design and architectural character is intended to simulate a traditional, real or imagined, Qatari village with covered alleyways and narrow pedestrian streets. Buildings are styled to represent a hybrid of traditional Arabic or Islamic features (Figure 2). The locale hosts artistic and professional organisations, lecture halls, theatres, art galleries and handicraft souqs, in addition to cafés and ethnic restaurants. The area selected for investigation within the village includes a large pseudo-Roman amphitheatre, a seafront esplanade that attracts strollers and people-watchers from different cultural backgrounds, and an entrance-fee 'public' beach that accommodates water sports and other beachside recreational activities. However, the village itself is designated for an exclusive clientele and patronage as it is gated; visitors are generally screened before being admitted.

The elegant Corniche Boulevard is, in striking contrast, the, lined with a seven-kilometre waterfront park and pathways, is one of the most important and accessible urban open spaces in Doha (Figure 3). It consists of an attractive linear

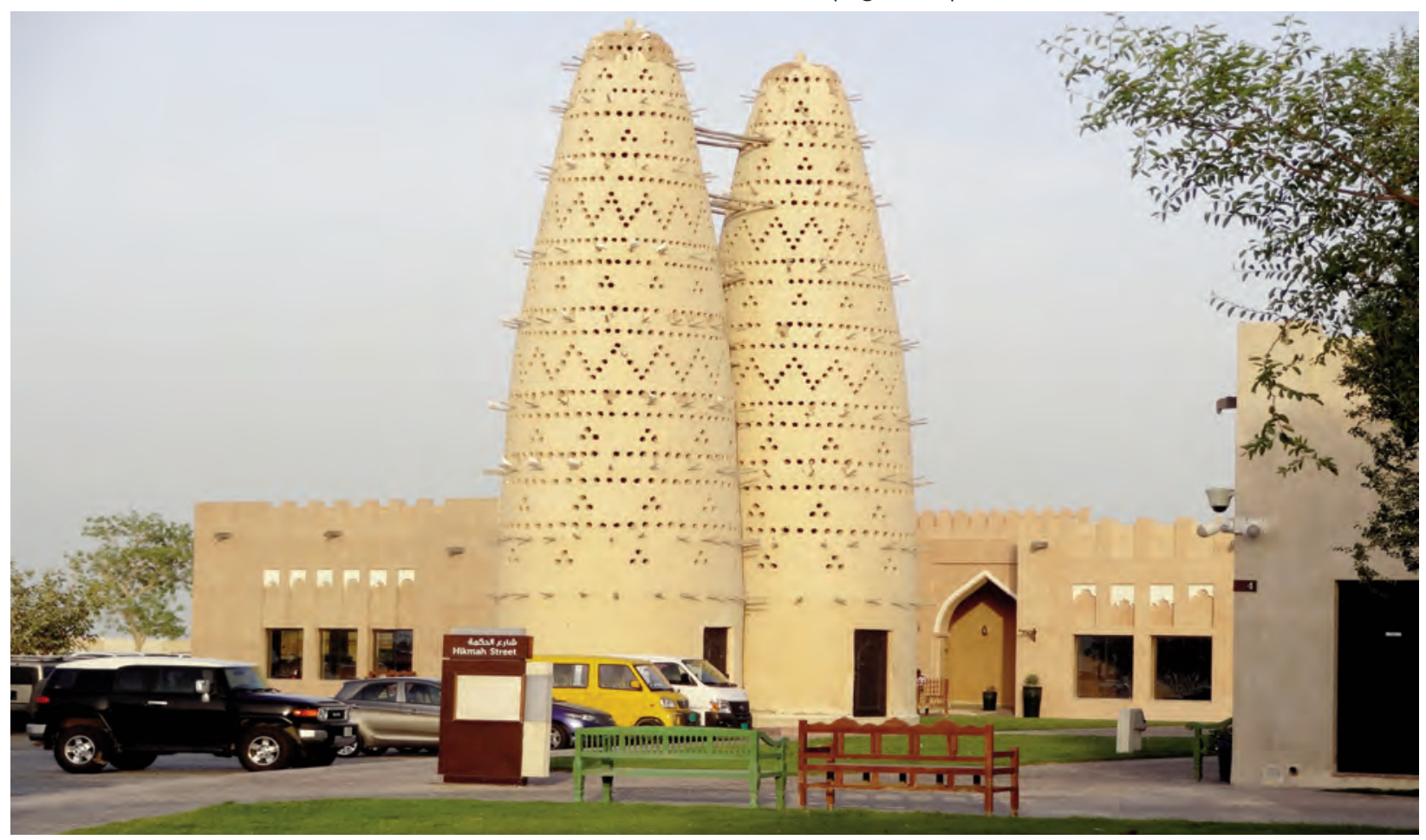

Figure 2. One of the access points at Katara Cultural Village. (Source: Authors). 


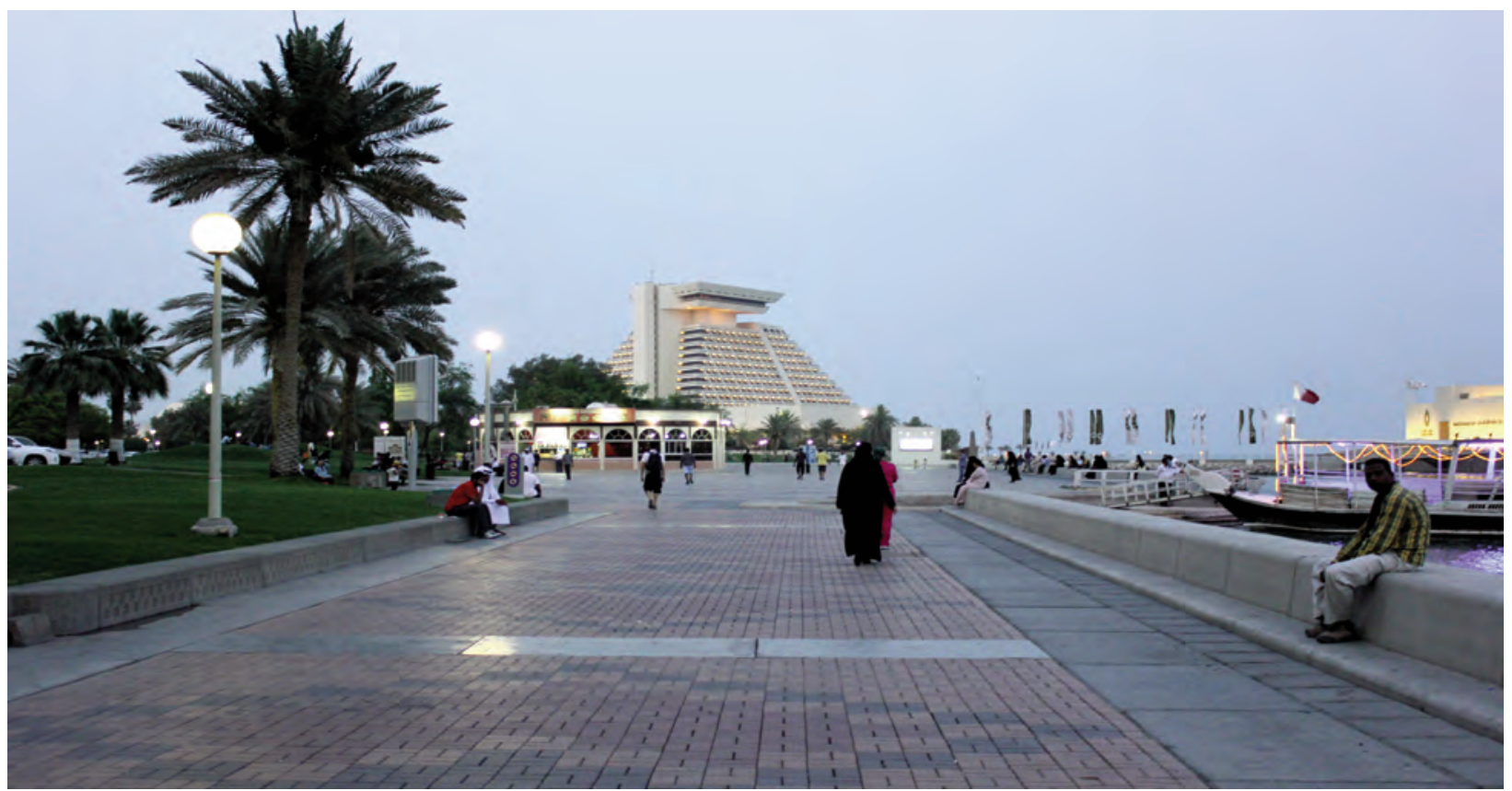

Figure 3. Corniche Area A, one of the most accessible urban open spaces in the city. (Source: Authors).

promenade or walkway along picturesque Doha Bay enhanced by a variety of landscaped green areas, entertainment areas, open spaces, and children's play areas. The Corniche Waterfront Park is a popular recreational spot which provides city inhabitants with opportunities for strolling, jogging, cycling or just sitting and contemplating the scenic views across the bay. The park attracts a wide variety of different cultural and socio-economic groups and is completely accessible to all members of the public. Key areas within the waterfront park can accommodate socialising, and sporting and cultural events and activities. One important area or space along the Corniche was selected for investigation. It is first is characterised by its proximity to The Sheraton Hotel, the first iconic building and oldest five star hotel in the city, and its lush green spaces, paths and cafeteria.
Souq Waqif, an important urban open space in Doha, is considered to be the most popular destination for residents and tourists alike. The rehabilitated Souq includes a wide variety of shops that sell traditional garments, souvenirs, spices, and foodstuffs within an environment that is designed to resemble the perceived and imagined traditional architecture of Qatar. The Souq is a combination of restored, reconstructed, renovated and new buildings (Figure 4). It also hosts several small boutique hotels, an art gallery, handicraft and antique shops, traditional markets, and numerous ethnic restaurants and cafés that attract Qataris, other Arabs, and expatriates from all income groups; from time to time labourers and groups of Asian men cruise through the open streets watching the more wellheeled patrons dine at expensive cafés and restaurants. Occasional or weekend festivals and events

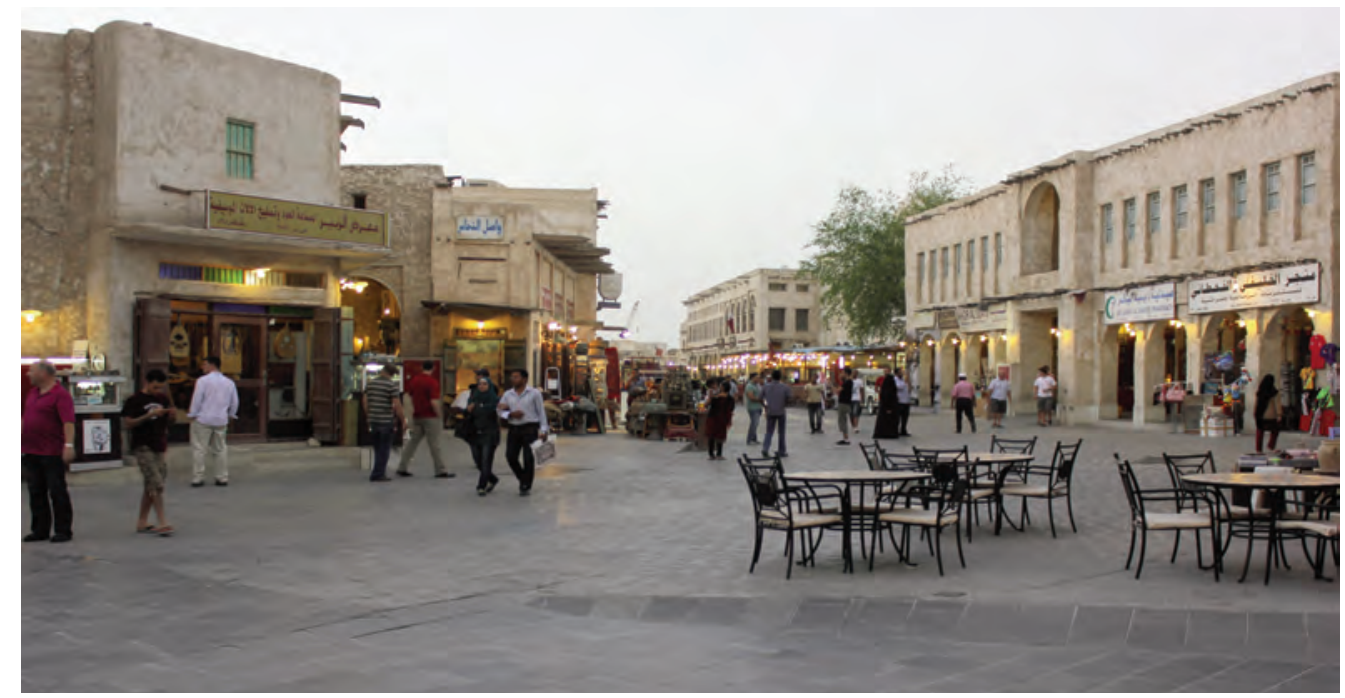

Figure 4. Main access and pedestrian spine of Souq Waqif. (Source: Authors). 
are held in the open areas of the Souq or in its purpose-built performing arts venue, the Al Rayyan Theatre. One important area within the Souq was selected for investigation: It includes the main pedestrian spine, which houses the police station and a series of ethnic restaurants and cafés. The Souq is very popular and parking is inadequate so finding a parking space is often a major problem exacerbated by the less than standard-size parking lozenges and narrow lanes of the car-park areas.

\section{SPACE CHARACTERISTICS: USE, ACTIVITIES AND BEHAVIOUR}

Katara Cultural Village: In observing the mixed types of users at the selected Katara Cultural Village space, including children and male and female visitors, the actual use can be clearly discerned (Figures 5 and 6). The users represent different socio-economic strata and cultural backgrounds, including a substantial presence of Qataris. Male labourers are represented in the space for restaurant staff and beach helpers. Female labourers are mostly cleaners or maids accompanying Qatari families to keep an eye on children. Cleaners seem to be available at all times, but appear to be moving more within the space in the evenings. Since most of the restaurants open late morning or at noon, the number of users is significantly less at these times than during the evenings. Beach use and activities are not common whether during the week or at weekends; this could be due to the high entrance fees. Even though the spaces, particularly the waterfront esplanade, are dark and poorly illuminated at night, Katara is more crowded in the evenings, both during weekday and weekend evenings. Interestingly, this lack of adequate lighting on the esplanade impacts in two contradictory ways; first of all, it enables substantial and most likely desired privacy for users, particularly Qataris, and secondly, it minimises the feeling of comfort and safety, which even so does not prevent people strolling along the esplanade in the concealing darkness.

Visitors are observed to go to Katara for different purposes. While many people visit the space to dine in the various restaurants or lounge in the numerous cafés and coffee shops, others prefer to go for a stroll along the esplanade or just sit on the few available seats and benches lining the main pedestrian walkways. It was observed that people walk or gather in groups, whether they are family members or a group of friends socialising. While strolling, they may glance at the representational architecture of the different buildings or just look for a suitable spot to sit. Some groups gather in front of the open-air amphitheatre to enjoy seaside views and the striking skyline of Doha; occasionally children play on the numerous steps and pediments of the gigantic amphitheatre. It was also noted that during the evening some people queve in front of busy popular or trendy restaurants, waiting to be seated. Overall, it was observed that both adults and children seem to enjoy their time in the space. However, the space lacks adequate outdoor furniture such as benches and chairs in addition to sufficient green spaces and landscaped features that would make it more amenable and attractive for use. The minimal use of green spaces creates a rather stark but not unpleasing leisure environment.

Corniche Area A: The mapping of Corniche Area A elucidates the reality of this space (Figures 7 and 8 ) and how it is actually used by a wide spectrum of people of different age groups and from different ethnic backgrounds. The space caters more to

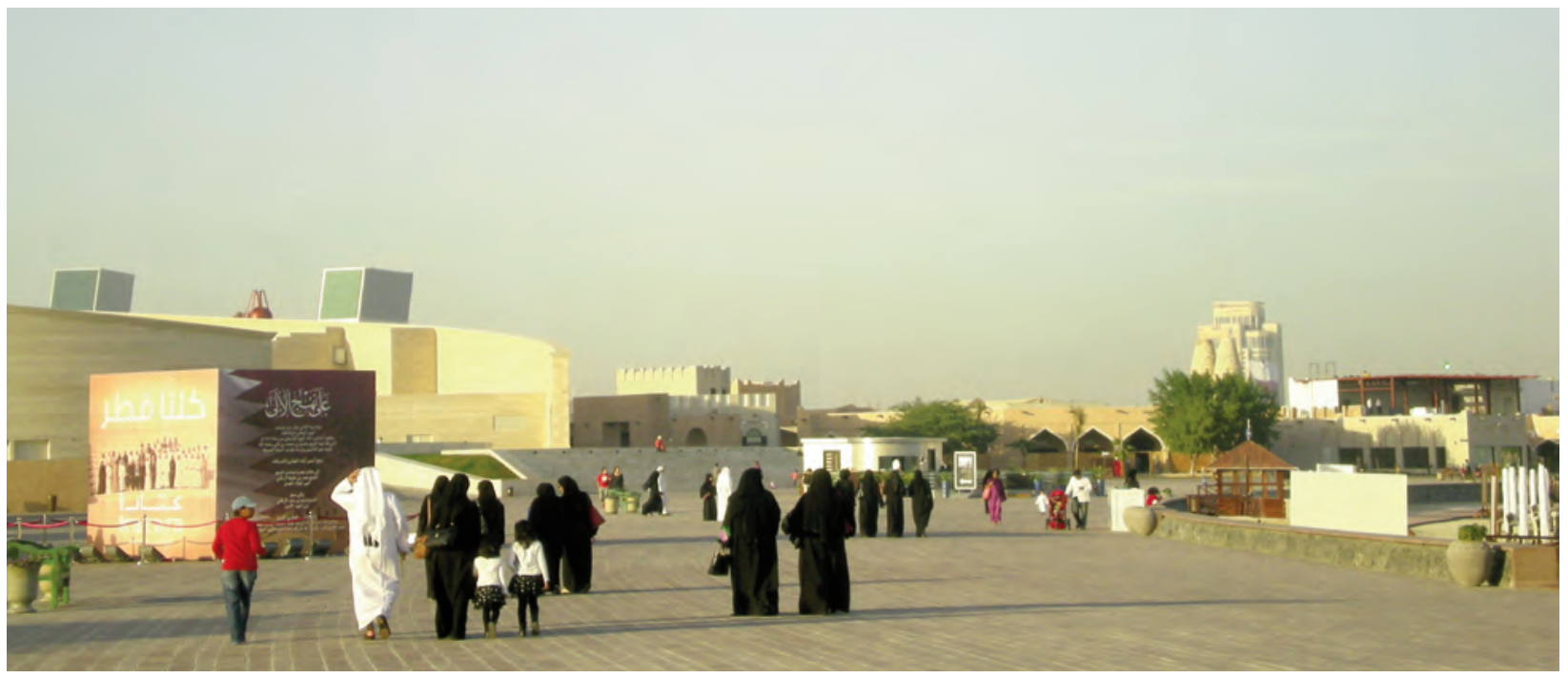

Figure 5. Substantial presence of Qatari families along the waterfront esplanade. (Source: Authors). 

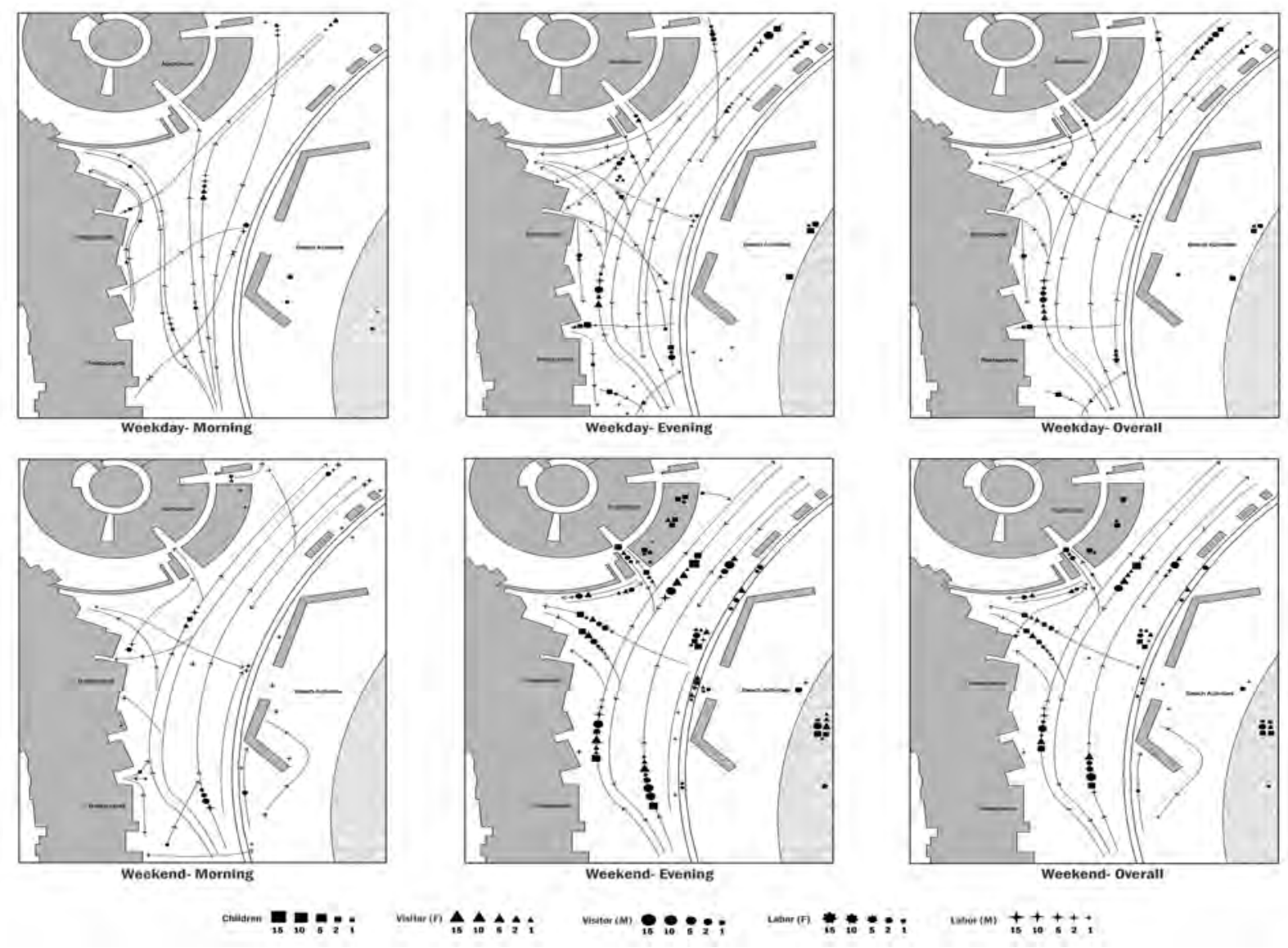

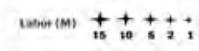

Figure 6. Generated behavioural maps based on observation periods at Katara Cultural Village. (Source: Authors).

lower and middle-income groups. A strong presence of male visitors is evident on weekday evenings; male labourers working in the space are also represented, these include cafeteria staff and Msheireb Enrichment Centre (MEC) security staff. Both males and females, taking exercise in the form of jogging, or casually strolling, were also recorded as passers-by. Additionally, the children's playground at the far northern end of the site is a major attraction for families. Family groups were also observed gathering in the space around the cafeteria, both in front of and behind it: in fact, the cafeteria appears to be the major attraction to the space, especially in the evenings when people come for refreshments. The space is generally crowded with different types of users on weekdays; at weekends they proliferate in the early morning and early evening. However, fewer users were noted on weekday mornings, probably due to the fact that most people are at work. In contrast, maintenance workers and gardeners were strongly represented in the mornings when they are on duty during hours where they are less likely to disturb visitors. It was also noted that a considerable number of male users visited the space specifically to drink traditional tea (karak) while sitting individually or in groups along the seawall, a protective barrier sep- arating the promenade from the sea, chatting and seemingly enjoying the views of the cityscape or the other side of the bay. Interestingly, motorbike riders (a very small interest group in the Doha population) were frequently noted congregating at the drop-off area, near the car-park.

Many users also passed by the major sidewalk or pavement, which runs parallel to the promenade, the major pedestrian spine that links the whole waterfront space of the Corniche Waterfront Park. The major activities appeared to be walking or stopping to use the rental bikes available in the green space near the cafeteria. Families were observed searching for a pleasant shady spot under a big tree, particularly near the children's play area, a space which is dotted with small trees on landscaped artificial hills and hummocks. Casual observation at other times, apart from scheduled behaviour mapping times, records that the space is more vibrant and more heavily populated during special events such as Qatar National Day celebrations and water sport events and competitions. While overall adults and children seem to enjoy spending their time there, pursuing their recreational interests and activities, the space lacks sufficient outdoor seating and significantly lacks parasols or other forms of shade, which could potentially make 


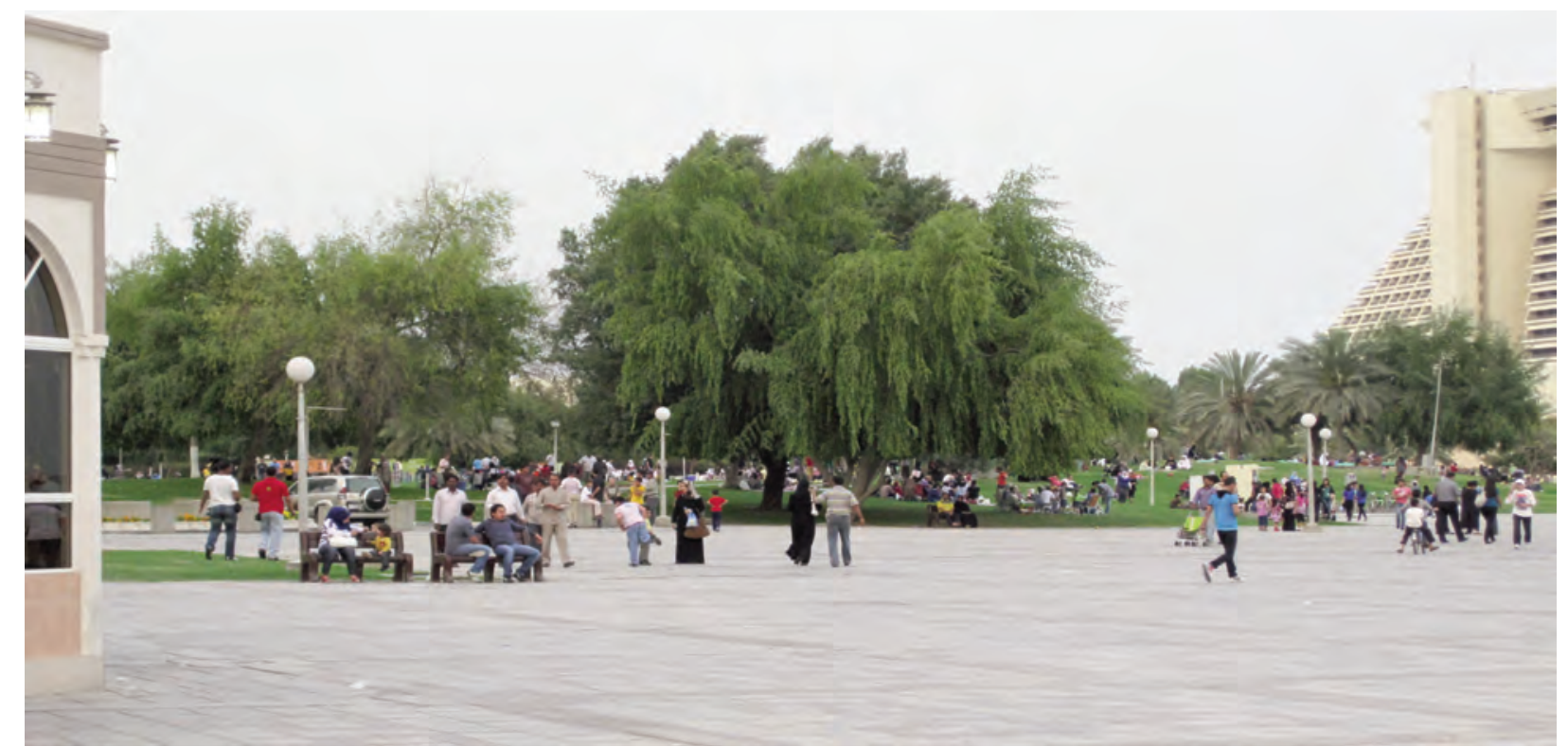

Figure 7. Individuals and groups congregate on pavements and green spaces at Corniche Area A. (Source: Authors).
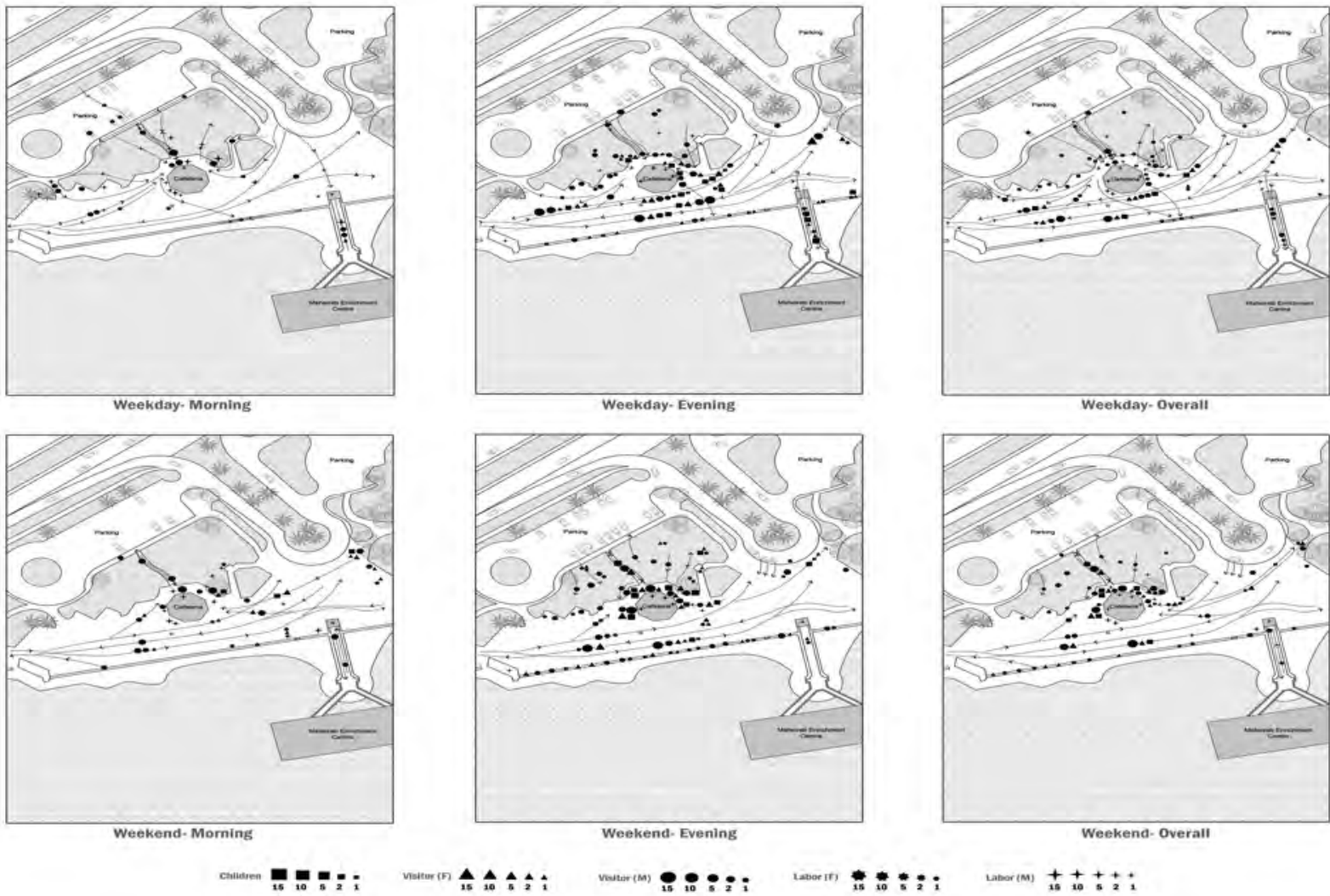

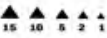

ำ:: : : :

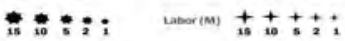

Figure 8. Generated behavioural maps based on observation periods at Corniche Area A. (Source: Authors).

it more appealing for use by more groups, especially during the hot and sunny daytime hours.

Souq Waqif as a rehabilitated traditional market and tourist destination area represents one of the most important and attractive leisure spaces in Doha; it caters to diverse groups including tourists, Qataris, and expatriate residents. Conducting behavioural mapping of the selected setting within the Souq reveals the authentic use of the space (Figures 9 and 10). It was observed that some Qataris and non-Qataris also visited the Police Station (Immigration Office) for various reasons, to authenticate documents or renew visas. Other users, including residents and tourists, frequented the space for dining or socialising purposes since the area has a diverse variety of ethnic restaurants 


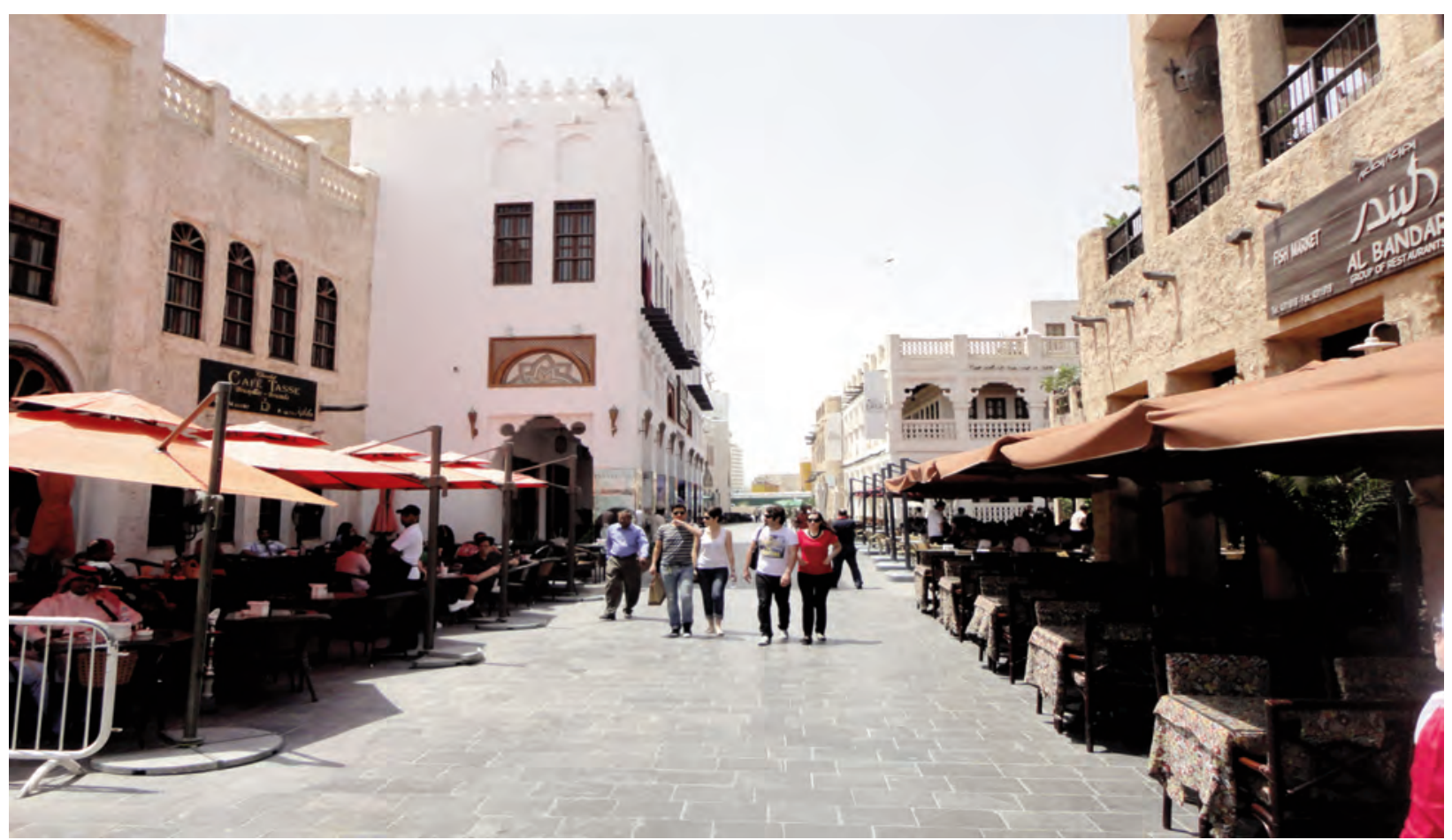

Figure 9. Visitors' activities in the main pedestrian spine of Souq Waqif. (Source: Authors).

and attractive outdoor cafés.

Tourists who stop over in Doha en route to other destinations often visited the space to shop, admire the 'traditional' architecture representative of the reconstructed and renovated Souq buildings, and experience or investigate some of the cultural
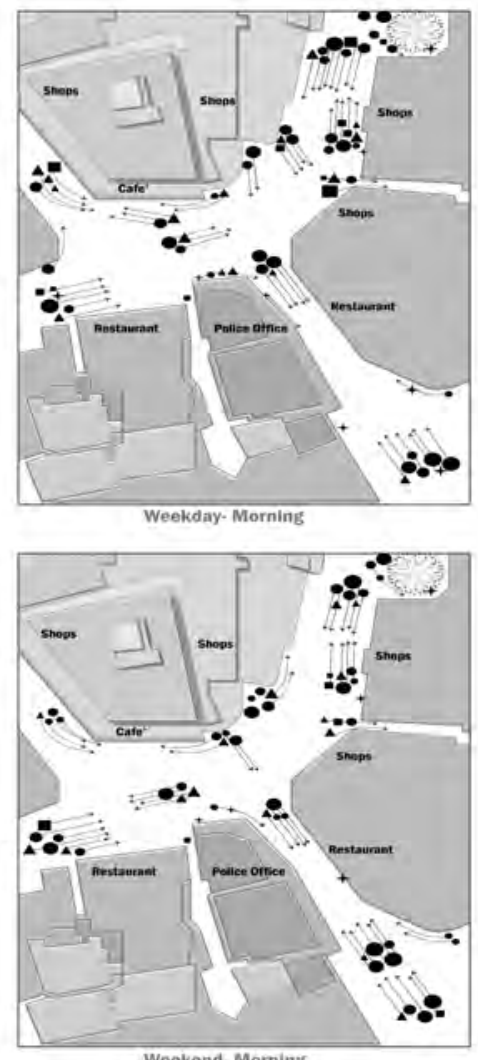

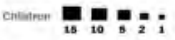
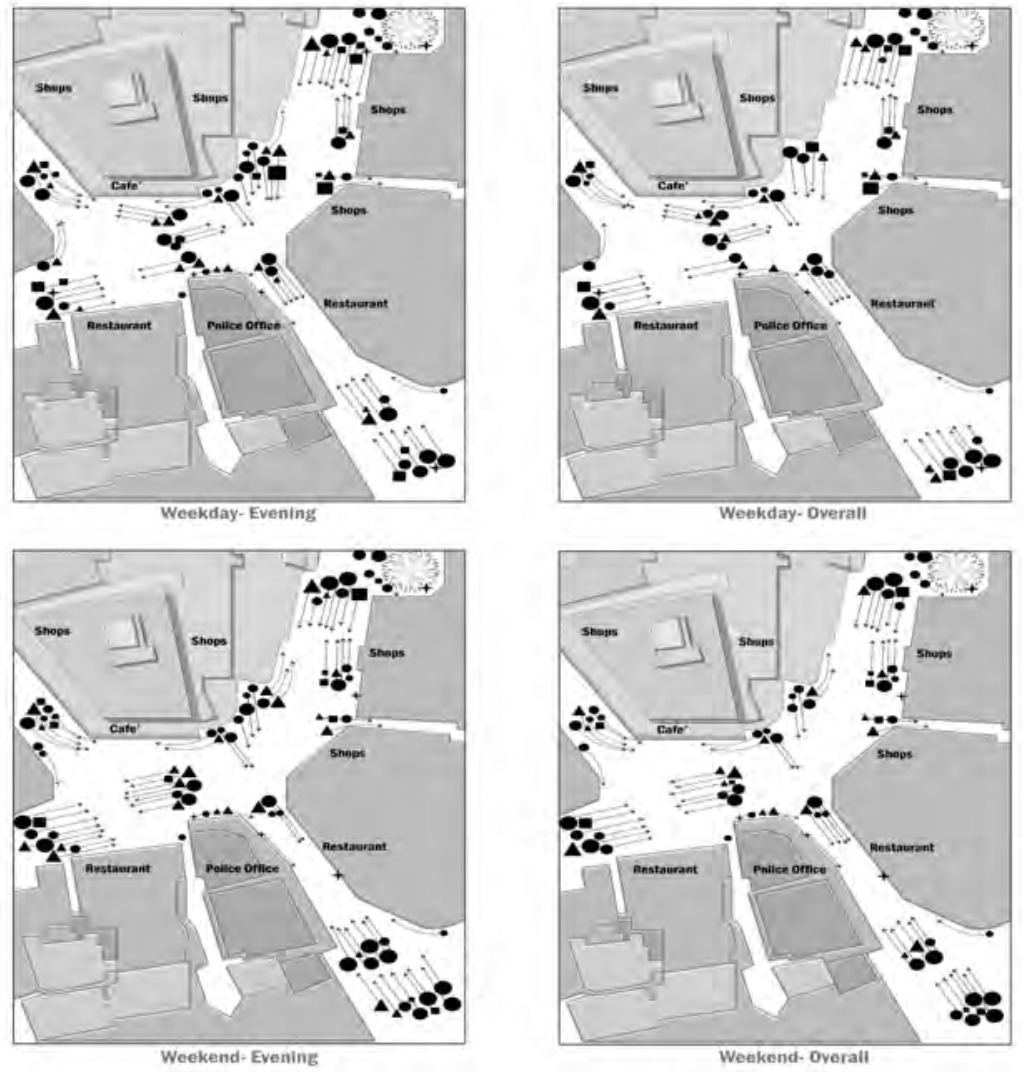

Figure 10. Generated behavioural maps based on observation periods at Souq Waqif. (Source: Authors). 
aspects of Qatar. Typically, groups of tourists were observed to visit traditional shops prior to relaxing in cafés or dining at one of the many restaurants. It was also noted that there was a very low representation of children, probably due to the lack of activities and facilities that would cater to them. Asian male workers would sometimes visit the space from nearby residential areas located south of the Souq. However, security police stand in front of and near the station and have been known to hustle certain visitors away, particularly unwelcome labourers or those who have been observed annoying visitors. Mounted policemen also frequently patrol the streets and are one of the attractions, especially for tourists.

The mapped space is one of the major arteries of the Souq; it is lined by various restaurants with roof terraces and outdoor cafés. In generic terms, the space is lively and well frequented both in the morning and evening. However, it is more vibrant at weekends than during the week, and in the evenings rather than the mornings. This is likely due to the restaurant and café opening times. Visitors generally go there for a meal or coffee with friends and family and some may go shopping. It was observed that the space was primarily used in the mornings as a passing-by space en route to the shops or the immigration office while in the evenings it was used for dining in restaurants or cafés, as well as shopping in the adjacent traditional market or handicraft shops. Crowds were bigger in the evenings rather than during the morning since the majority of visitors, other than tourists, were more likely to be at work. The space, as part of a pedestrian passageway to the traditional market area, seemed to be functioning very well; however, the complete lack of children-oriented activities and venues was also noted.

\section{CONCLUSION}

This paper presented narrated results of the examination and assessment of three important urban open spaces in the city of Doha. With observing the location, activities, and the people involved, behavioural mapping procedures offer insights into understanding the influence of cues on users such as the availability or lack of furniture like benches or picnic tables, furnishings such as parasols or shade, and equipment such as children play equipment, in addition to the physical features of the spaces. Recording the character and type of activities, and the casual factors associated with them, can assist in the identification and subsequent understanding of movement patterns that are often governed by design qualities and amenities that characterise the space.

The overall experience of users in the three spaces examined appears to be satisfactory. Yet, it demonstrates that people experience and interact with urban open spaces differently and as such their needs vary according to the purpose for which they visit the space. The mapping studies of urban open spaces delineate the fact that there is an absence of landscape features and a dearth of green spaces of appropriate outdoor furniture, such as benches and seating, in Katara Cultural Village; similarly, there is an absence of adequate shaded areas and shading devices in the Corniche Area A. In addition, a lack of children's facilities or a specially designated area for children was noted in Souq Waqif. These observed lacks and absences could be viewed as deficiencies that hinder the maximum efficient and effective utilisation and use of such spaces. Addressing the lack of features that enhance people's activities and use of the space, or those that would cater to a specific type of user would make the space more conducive for use by different types of users and at different days and times.

The rapid speed of recent urban development in Doha has mandates an urgent need to examine the various layers of interdependencies between an emerging society and newly built urban fabrics and spaces. The tendency of supply-driven parameters within local urbanism has led to restricted participation among inhabitants in shaping Doha's built environment in recent years. The shift from the phenomenon of an 'instant city' to a consolidated and attractive international hub will, however, rely on increased individual identification to urban spaces and a more satisfying fulfilment of the demands and desires of a wide spectrum of user types in terms of urban design.

\section{ACKNOWLEDGEMENT}

This study is developed as part of a comprehensive funded research project of the National Priorities Research Program, QNRF-Qatar National Research Fund (NPRP 09 - 1083 - 6 - 023). 


\section{REFERENCES}

AKKAR, M. 2005. Questioning the "Publicness" of Public Spaces in Postindustrial Cities, in Traditional Dwellings and Settlements Review, XVI(1 1), 75-91

CARR, S., FRANCIS, M., RIVLIN, L. G., and STONE, A. M. 2012. Needs in Public Space, in M. Carmona and S. Tiesdell (eds.), Urban Design Reader, The Architectural Press, Oxford, 230-240.

CHAFTOE, H. 2008. Convivial Urban Spaces: Creating Effective Public Places, Earthscan, London.

DOVEY, K. G. 2002. Pleasure, politics and the 'public interest': Melbourne's riverscape revitalization, in Journal of the American Planning Association, 68(2), 151-164.

ELSHESHTAWY, Y. 2011 . Informal Encounters: Mapping Abu Dhabi's Urban Public Spaces, in Built Environment, 37(1), 92 113.

GEHL, J. 1987. Life Between Buildings: Using public spaces. Van Nostrand Reinhold, New York, NY.

JACKSON, J. B. 1981. The public park needs appraisal, in L. Taylor (ed.), Urban Open Spaces Rizzoli, New York, NY, 34-35.

LINDAY, N. 1978. It all comes down to a comfortable place to sit and watch, in Landscape Architecture, 68 (6) 492-497.

NEWMAN, O. (1972), Defensible Space: People and Design in the Violent City, The Architectural Press, Oxford.

SALAMA, A. M. and GHARIB, R.Y. 2012. A Perceptual Approach for Investigating Urban Space Diversity in the City of Doha, in Open House International, 37(2), 24-32.

SALAMA, A. M. and WIEDMANN, F. 2013. Demystifying Doha: On Architecture and Urbanism in an Emerging City. Ashgate Publishing Ltd., Surrey.

SALAMA, A. M. 2012. Assessing Qatar University's Campus Outdoor Spaces: Design Intentions Versus Users' Reactions. In S. Mallory-Hill, W. Preiser and C. Watson (eds.) Enhancing Building Performance, John Wiley and Sons, New York, NY, 139-150.

SANOFF, Henry. 1991. Visual Research Methods in Design. Van Nostrand Reinhold, New York, NY.

VARNA G. and TIESDELL, S. 2010. Assessing the Publicness of Public Space: The Star Model of Publicness, in Journal of Urban Design. 15(4), 575-598

WHYTE, W. H. 1980. The Social Life of Small Urban Spaces. Conservation Foundation, Washington, DC.
WIEDMANN, F., SALAMA, A. M. and THIERSTEIN, A. 2012. Urban Evolution Of The City Of Doha: An Investigation Into the Impact of Economic Transformations on Urban Structures, in JFA/METU: Journal of the Faculty of Architecture. 29(2), 35-61.

WOOLLEY, H. 2003. Urban Open Spaces. Spon Press, London.

\section{Author(s):}

\section{Prof. Ashraf M. Salama}

Professor of Architecture and Urbanism, Head, Department of Architecture and Urban Planning, Qatar University.

Email: asalama@qu.edu.qa

\section{Fatima Abdulla Khalfani}

Postgraduate Student - Master of Urban Planning and Design, Department of Architecture and Urban Planning, Qatar University.

Email: 200464524@qu.edu.qa

\section{Ahood Abdullah Al-Maimani}

Postgraduate Student - Master of Urban Planning and Design, Department of Architecture and Urban Planning, Qatar University.

Email:200662469@qu.edu.qa 